\title{
Body Weight and Shape Self-Cognitions, Emotional Distress, and Disordered Eating in Middle Adolescent Girls
}

\author{
Karen Farchaus Stein and Kristen M. Hedger
}

\begin{abstract}
In this study, stability of the body weight/shape self-schema and possible self in a sample of middle adolescent girls during their transition from junior high to high school was examined and the relationship between these self-cognitions and emotional distress and disordered eating behaviors was explored. Subjects $(N=79)$ completed measures of self-cognitions, competence, and self-esteem in the 8th and 9th grades. Disordered eating and depression were measured in 9 th grade. Eighth grade self-schema scores were used to identify the fat/out-of-shape $(n=21)$ and thin/athletic $(n=20)$ self-schema groups. For both groups, stability in the body weight/shape cognitions was found. Girls in the fat/out-of-shape group had lower self-esteem, appearance, and athletic competence scores in both grades and higher dieting and depression scores in 9th grade than the slim/athletic group. Regression analyses showed that the self-schema score was a stronger predictor of the outcomes than weight. Findings suggest that the body weight/shape self-schema plays an important role in adolescent girls' emotional health.

Copyright $₫ 1997$ by W.B. Saunders Company
\end{abstract}

\begin{abstract}
A MONG ADOLESCENT GIRLS, the prevalence of disordered eating behaviors is rising sharply. Recent studies suggest that $30 \%$ to $50 \%$ of early and middle adolescent girls consider themselves overweight whereas as many as $25 \%$ engage in subthreshold levels of disordered eating behaviors including dieting, fasting, diet pill use, binge eating, and purging (Felts, Parrillo, Chenier, \& Dunn, 1996; Koff \& Rierdan, 1991; Wardle \& Marsland, 1990). At all levels, these behaviors are associated with emotional and physical health consequences (French, Story, Downes, Resnick, \&
\end{abstract}

From the University of Michigan, School of Nursing, Ann Arbor, MI.

Supported by the National Institute of Nursing Research, NIH, P20 NR02962, Exploratory Center for Child/ Adolescent Health Behavior Research, Nola Pender, RN, PhD, Director.

Address reprint requests to Karen Farchaus Stein, PhD, RN, 400N. Ingalls St, Ann Arbor, Ml 48109. Copyright $\odot 1997$ by W.B. Saunders Company 0883-9417/97/1105-0006\$3.00/0
Blum, 1995) and for some girls, they reflect the initial phase of a trajectory toward a diagnosable eating disorder (French, Perry, Leon, \& Fulkerson, 1995; Graber, Brooks-Gunn, Paikoff, \& Warren, 1994).

Not surprisingly, efforts to understand the cause of the disturbed eating attitudes and behaviors in adolescents have tended to focus heavily on body image. Building on the broad collection of research on body image in anorexia nervosa and bulimia nervosa, investigators interested in the early onset of subthreshold levels of disordered eating behaviors have begun to direct their attention toward this component of the internal representational system. Yet despite the fact that there is growing recognition within the field that body image is a complex, multidimensional construct that includes perceptual, conceptual and affective information about the physical self (Cash \& Brown, 1987; Kihlstrom, Cantor, Albright, Chew, Klein, \& Niedenthal 1988; Rosen, 1990) the majority of adolescent studies 
completed to date have tended to focus more narrowly on the affective dimensions of the body image representation. These studies have explored the link between feelings of dissatisfaction toward one's physical self and attitudes toward food, mood, global self-esteem, and dieting and purging behaviors (see Adams, Katz, Beauchamp, Cohen \& Zavis, 1993; Castro \& Goldstein, 1995; French et al., 1995; Graber et al., 1994 for examples). Few studies have focused on body image as a conceptually-based mental representation, exploring the content and structure of this self-definition in adolescent girls. In this study, the self-schema model (Markus, 1977; Markus \& Wurf, 1987) was used as the theoretical framework to investigate the nature and consequences of the current and futureoriented representations of the physical self in a sample of middle adolescent girls.

\section{THE SCHEMA MODEL: A THEORETICAL FRAMEWORK FOR BODY IMAGE AND DISORDERED EATING}

The schema model has been identified as a potentially powerful explanatory model for addressing the relationships between body image cognitions and disordered eating attitudes and behaviors (Stein, 1996). Its power stems from the fact that its theoretically derived and empirically supported propositions can be used to develop a parsimonious explanation of how the cultural valuing of thinness can become a personalized internal regulator of eating attitudes and behaviors.

According to Markus (1977), a self-schema is a complex organization of knowledge about the self in a specific behavioral domain. It is a rich, highly elaborated system of mental representations that is formed through interaction with the environment. Although categorizations and evaluations of one's physical self and behavioral characteristics made both by the self and others play an important role in the formation of the self-schemas, recent studies have shown that the self-representations are also shaped by the norms, values, and ideals of the cultural context (see Markus \& Kitayama, 1991 for review). Prevailing cultural messages focus the individual's attention on specific aspects of the self, and accepted norms and ideals become the standards against which the individual is evaluated and defined. In the body image domain, a variety of cultural icons serve to focus the individual's attention on body weight and shape as an important source of self-definition (Guillen \& Barr, 1994) whereas unique characteristics of the individual (i.e., actual body weight and rate of sexual maturation) and the immediate social environment (i.e., peer teasing and maternal attitudes toward body weight) further shape the individual's relative valuing of her physical self and the specific content of her body image (Cash, 1995; Pike \& Rodin, 1991; Rieves \& Cash, 1996; Striegel-Moore, Silberstein \& Rodin, 1986).

Although components of the body image such as body dissatisfaction, feelings of fatness, and drive for thinness are frequently identified as important determinants of negative affect and disordered eating, the mechanisms to explain the associations are not addressed. One important advantage of the self-schema model is that it provides an explanation of how cognitions about the self function to regulate emotional and behavioral responses (Greenwald \& Pratkanis, 1984; Markus \& Wurf, 1987). Self-schemas are conceptualized as hierarchically organized structures with abstract, conceptual, or semantic knowledge at the top and context-specific episodic memories nested below (Kihlstrom et al., 1988; Taylor \& Crocker, 1981). Important to the issue of emotional and behavioral regulation is the fact that self-schemas also include procedural knowledge-action-based memories in the form of motoric skills, habits, rules, and strategies for making judgments, drawing inferences, and accomplishing goals relevant to the domain (Cantor \& Kihlstrom, 1987). In a study on the functional properties of the body weight self-schema, Markus showed that individuals with an overweight selfschema not only processed information relevant to that self-definition more efficiently but also were more consistent in body weight judgments about themselves across a variety of stimuli (Markus, Hamill, \& Sentis, 1987). Furthermore, the availability of an overweight self-schema affected the speed and efficiency of judgments about the desirability of food. In addition to strategies for evaluating and drawing inferences about the physical self, behavioral routines such as dieting, bingeing, and purging may also be encoded within the body image schema as procedural knowledge and enacted each time the schema is activated in working memory.

Self-schemas include not only knowledge of who the self is today, but also conceptions of the self one was in the past and visions of the self one wants to be in the future (Markus \& Nurius, 1986). 
The future-oriented conceptions, referred to as possible selves, have also been shown to play a powerful role in motivating and organizing goaldirected behavior (Hooker, 1992; Ruvolo \& Markus, 1992). Particularly within the body image literature, discrepancies between the current self and the wished-for or feared selves have been conceptualized as a powerful motivating force that organizes and energizes the disordered eating behaviors (Strauman, Vookles, Berenstein, \& Higgins, 1991; Szymanski \& Cash, 1995). In addition, the discrepancies are seen as the source of negative emotions and attitudes toward the self (Higgins, 1987).

To function as reliable behavioral regulators, the self-schemas and possible selves must be stable and enduring components of the cognitive system. Although studies have shown stability of the selfschemas and possible selves in a variety of domains in young adult populations (Markus, 1977; Stein, 1994), the level of stability of the body weight and shape self-schema and possible self in adolescent girls is unknown. The self-concept is generally considered unstable during adolescence (Rosenberg, 1986). Biological, cognitive, and social changes that occur during adolescence challenge childhood self-definitions and lead to a period of disorganization during which new and revised self-conceptions are formed (Harter \& Monsour, 1992; Orenstein, 1994; Wigfield, Eccles, MacIver, Reuman, \& Midgely, 1991).

In the body weight and shape domain, studies have shown that the physical changes surrounding menarche, including the rapid increase in proportion of body fat and breast development cause changes in the feelings and beliefs about the physical self (Attie \& Brooks-Gunn, 1989; Slap, Khalid, Paikoff, Brooks-Gunn, \& Warren, 1994). Yet the findings of studies that have shown stability in eating attitudes and behaviors through the middle to late adolescent years (Graber et al., 1994) offer some evidence to suggest that by this stage in development, the body weight and shape selfcognitions may be consolidated into enduring structures. Because the physical changes associated with menarche generally occur relatively early in adolescence (Brooks-Gunn \& Reiter, 1990), the task of redefining the physical self may be one of the first to be "worked on" and resolved. For adolescent girls, the heightened salience caused by interpersonal and intrapersonal attention to the domain during this time rapid of physical change may lead to an earlier consolidation of the body weight and shape self-schema and possible self.

In this longitudinal study, the stability of the body weight and shape self-schema and possible self in a sample of middle adolescent girls during their transition from junior high to high school was examined and the relationship between these selfcognitions and emotional distress and disordered eating attitudes and behaviors was explored. Building on previous research that suggests that the body image representation in contemporary American society not only includes information about body weight or adiposity but also information about fitness or muscular tone (Garfinkel, 1992; Guillen \& Barr, 1994; Rodin, 1993), the stability and consequences of two distinct types of body image self-schemas were explored; the fat and out-ofshape self-schema and the slim and athletic selfschema. The junior high to high school transition was chosen for the study because for most girls, it occurs after menarche and is a time when subthreshold levels of disordered eating attitudes and behaviors are prevalent (Graber et al., 1994).

Two research hypotheses were tested: (1) The body weight and shape self-schema and possible self will remain stable in a sample of middle adolescent girls across the junior high to high school transition; (2) Girls with a fat and out-ofshape self-schema will experience higher levels of emotional distress and disordered eating attitudes and behaviors that those with a slim and athletic self-schema.

\section{METHOD}

\section{Study Overview}

The data for this study were collected as part of a 2-year longitudinal project that focused on the role of cognitions about the self in regulating the performance of health-promoting and risk-taking behaviors in adolescents.

\section{Subjects}

Subjects were recruited from a single public junior high school in a suburban community that could be characterized as primarily working class. In this school system, junior high school extended through the 8th grade and high school included 9th through 12 th grades. All students in the 8 th grade class were informed of the study and invited to participate. A total of 160 8th grade students 
participated in the larger project. This study focuses on the 79 girls included in the sample.

The mean age of the girls was $13.5(S D=0.6)$ years. Eighty-one percent of the girls were White $(n=64), 14 \%$ were African American $(n=11)$, $4 \%$ indicated other $(n=3)$, and $1 \%$ did not respond to the question about race $(n=1)$.

Data were collected at two points in time: winter terms of the 8th and 9 th grades. Of the original 79 girls, 86\% ( $n=68)$ completed both the 8th and 9th grade measures. Eleven subjects dropped out of the study for a variety of reasons including family relocation and changes in schools. The girls who dropped out of the study were significantly older $(M=14.1, S D=0.8)$ than those who were retained $(M=13.3, S D=0.5), t(12.67)=3.12, p=$ .008 . No significant differences in race, 8 th grade self-reported body weight, global self-esteem nor body weight and shape self-schema and possible self scores were found between those who dropped out of the study and those who were retained.

\section{Measures}

Me now and in the future. A questionnaire based on a format developed by Markus and Nurius (1986) was used to measure the body weight and shape self-schema and possible self. The questionnaire consists of 31 self-descriptors designed to measure self-schemas and possible selves in seven content domains. For each descriptor, three questions are asked: (1) How much does it describe me now, (2) Will it describe me in the future, and (3) How likely is it that it will describe me in the future. Responses to the first and third questions were used for this study. A 5-point scale anchored by "not at all" at one end and "very much" at the other was used for both questions. Responses to the first question were used to measure the content of current self-schemas; whereas responses to the third question were used to measure the content of possible selves.

The body weight and shape self-schema was measured with a 5-item subscale that included three positively worded items (slim, fit, and athletic) and two negatively worded items (fat and out-ofshape). The two negatively worded items were reverse coded to be consistent with the direction of the other items in the scales. The subscale score is the mean of the five item responses to the "describes me now" question. The same five selfdescriptors (slim, fit, athletic, fat, and out-of-shape) were used to measure the body weight and shape possible self. The possible self subscale score is the mean of the five item responses to the "likely to describe me in the future" question. For these two subscales, a high score (maximum of 5) indicated a slim and athletic self-schema or possible self whereas a low score (minimum of 1 ) indicated a fat and out-of-shape self-schema or possible self.

To assess the validity of the body weight and shape self-schema subscale, correlations between the body weight and sports/athleticism scores of the All About Me questionnaire and the self-schema subscale score were examined. The All About Me questionnaire is an open-ended format questionnaire in which subjects were asked to list all the descriptors that are "important to making you who you are" (see Stein, Markus, \& Roeser, 1997). The self-generated descriptors were then independently content coded by two research assistants using a scheme that included the domains of body weight, involvement in sports, and athleticism (agreement between the 2 coders across the total sample of 160 cases was $83 \%$ ). For each category, a score was created that reflects the number of self-descriptors generated by the subject in the category. To reduce the effects of priming with an open-ended measure, the All About Me Measure was administered first in the protocol before any closed-ended format measure was given. It was expected that subjects with a low score on the body weight and shape selfschema subscale (i.e., fat and out-of-shape selfschema) would be more likely to spontaneously define themselves as overweight on an open-ended measure than those with a high subscale score (i.e., thin and athletic self-schema). Similarly, we expected that those with a high subscale score (i.e., slim and athletic self-schema) would be more likely to generate self-descriptors related to their involvement in sports and their athleticism. Consistent with our predictions, both the 8th and 9th grade current body weight and shape self-schema scores were negatively correlated with the number of overweight descriptors generated $(r=-.37$ and $-.42, p=.01$ ) and positively correlated with the number of sports and athleticism descriptors $(r=.31$, and $.26, p=.01$ ), providing evidence to support the validity of the body weight and shape self-schema subscale.

Cronbach alpha coefficients for the body weight and shape self-schema in the 8th grade was . 77 and in the 9 th grade was .80 . For the body weight and 
shape possible self subscale, the Cronbach alpha coefficient for the 8th grade was .72 and for the 9th grade was .70 .

To assess the test-retest reliability of the measure, the questionnaire was pilot tested on a sample of 69 8th grade girls at a public junior high school in a different but comparable community. The questionnaire was administered on two occasions approximately 2 weeks apart. The Pearson correlation coefficient between the time 1 and time 2 body weight and shape current self-schema subscale scores was .82 and for the possible self subscales was $.64(p<.01)$.

Adolescent activity log. A diary-type questionnaire developed by Garcia, George, Coviak, Antonakos, \& Pender (1996) was used to measure average daily duration of exercise. The questionnaire consists of a list of 16 physical activities. For each item, the subject indicates whether she participated in the activity in the last day (yes/no) and if so, the duration of participation. To account for seasonal variation, the measure was administered in the winter and spring of the 8th grade and the fall, winter and spring of the 9th grade. At each administration the questionnaire was completed for a 7-day interval including a weekend. Subjects completed the diary for the previous day at school during the morning homeroom period. Diaries for Friday, Saturday, and Sunday were completed on Monday. The score was computed by dividing the total number of minutes exercised by the number of days of valid data. A score was computed only on subjects who completed at least 4 days of diaries for each week of data collection. Evidence to support the validity and reliability of the measure with adolescent populations has been shown (Garcia et al., 1996).

Body weight. The Adolescent Activity Log included a self-reported measure of weight. Weight reported during the winter administrations of the log was used in this study. Evidence to support the validity of self-report weight has been shown (Attie \& Brooks-Gunn, 1989; Garcia et al., 1996).

Menstrual status. A health behavior questionnaire included two self-report measures of menstrual status. Evidence to support the validity of self-reported menstrual status has been shown (Brooks-Gunn, Warren, Rosso, \& Gargiulo, 1987).

Three outcome measures were also completed.
The Self-Perception Profile for Adolescents (SPPAQ). A 45-item questionnaire developed by Harter (1988) was used to measure judgments of personal competence in eight behavioral domains including scholastic, social acceptance, athletics, physical appearance, job, romantic appeal, behavioral conduct, and close friendships. In addition, a 5-item measure of global self-esteem is included. Items are presented in a structured alternative format designed to reduce social desirability effects. Evidence to support the validity and reliability of the measure with junior high and high school level samples has been shown (Harter, 1990; 1988).

Hopkins Symptoms Checklist (SCL-90)-Depression Subscale. A 12-item subscale of the SCL-90 (Derogatis, 1992) was used to measure symptoms of depression. A thirteenth item that focuses on sexual interest and pleasure was deleted from the scale because of the age of the sample. Scores for this subscale are the mean based on the number of items with valid responses (Derogatis, 1992). Evidence to support the validity and reliability of the measure with nonpatient adolescent populations has been shown (Derogatis, 1992).

Eating Attitudes Test (EAT-26). A26-item questionnaire developed by Garner, Olmstead, Bohr, \& Garfinkel (1982) was used to measure symptoms and concerns associated with eating disorders. The questionnaire consists of 3 subscales (Dieting, Bulimia/Food Preoccupation, and Oral Control). Items were scored using the procedure described by Garner and Garfinkel (1979). Evidence to support the validity and reliability with adolescent samples has been reported (Wood, Waller, Miller, \& Slade, 1992).

\section{Procedures}

A letter explaining the study and a parental consent form were mailed to the home of each 8th grader in the school (total of 239 students). Those adolescents who received parental consent were invited to participate. The questionnaires were completed during two data collection sessions. In the first session, the subject met individually with an interviewer in a private room. After completing the assent form, subjects completed the All About Me questionnaire followed by the Me: Now and in the Future questionnaire. The second session, which occurred approximately 3 weeks later, was a group administration of a booklet of written questionnaires that included the SPPAQ. The EAT-26 and 
SCL-90 (Depression Subscale) were included in the booklet in the 9th grade testing only. Directions for the questionnaires were read aloud and subjects were monitored as they completed the measures. Interviewers were sophomore and junior level undergraduate students who were taught basic interviewing skills and use of the questionnaires in training sessions that lasted approximately 20 hours.

\section{RESULTS}

\section{Identification of Fat/Out-of-Shape and Slim/Athletic Schematic Groups}

For the purposes of examining the stability of the body weight and shape self-schema and possible self and their impact on emotional distress and disordered eating behaviors, two groups of subjects were identified; girls who defined themselves as fat and out-of-shape and girls who defined themselves as slim and athletic. Placement in the fat/out-ofshape and slim/athletic self-schema groups was determined by the subject's 8 th grade body weight and shape self-schema subscale score. A quartile split was used to identify the two groups. For the total sample, the mean body weight and shape subscale score was $3.53(S D=0.81$, Range $=1.00$ 4.80 ). Subjects whose subscale score placed them in the bottom 25 th percentile (scores ranging from 1.00 to 3.00 ) were identified as the fat/out-of-shape self-schema group $(n=21)$ and those whose score placed them in the upper 75th percentile (scores ranging from 4.20 to 4.80 ) were identified as the slim/athletic self-schema group $(n=20)$.

To examine the relationship between selfschema group placement and objective body weight over time, a mixed model analysis of variance was completed and followed by $t$-tests and paired $t$-tests when appropriate. In this model, group (fat/out-ofshape; slim/athletic) was the between subject factor and time (8th and 9 th grade) was the within subject factor. Self-reported 8 th and 9th grade weights were used as the dependent variables. Results revealed a significant main effect for group, $F(1$, $25)=11.01, p=.003$, with the fat/out-of-shape group reporting higher body weights in the 8th grade $(M=129.1, S D=21.0)$ when compared with the slim/athletic self-schema group $(M=105.2, S D=11.9), t(19.65)=3.78, p=.001$ and in the 9th grade (Fat/out-of-shape: $M=134.5$, $S D=20.4$ versus slim/athletic: $M=115.4$, $S D=12.4), t(30)=3.26, p=.003$. A significant time effect was also found, $F(1,25)=11.01, p=$
.003 . However, the main effects were qualified by a significant group $\times$ time interaction effect, $F(1,25)=5.70, p=.03$. Results of paired $t$-tests revealed that girls in the slim/athletic schema group reported a significant increase in body weight across the 8th to 9th grade transition, $t(14)=$ $-4.30, p=.001$, whereas no change in weight was found for the fat/out-of-shape schema group, $t<1$.

For activity level, the 8th and 9th grade daily average number of minutes spent exercising were used as the dependent variables in a mixed model analysis of variance. Results revealed a significant main effect for group, $F(1,35)=5.66, p=.02$, with the slim/athletic group reporting more minutes spent exercising per day in the 8th $(M=69.7$, $S D=49.4$ ) than the fat/out-of-shape group $(M=40.7, S D=21), t(25.92)=-2.41, p=.02$. No significant group difference was found in the 9th grade (slim/athletic: $M=55.4, S D=30.2$ versus fat/out-of-shape: $M=44.9, S D=23.7$ ), $t(35)=-1.19, p=$ NS. No significant effect for time was found. However, the significant group $\times$ time interaction, $F(1,35)=3.97, p=.05$, revealed that the slim/athletic self-schema group reported a marginally significant decrease in the average number of minutes spent exercising daily in the 9th grade compared with 8 th grade, $t(17)=1.88, p=$ .08 , whereas no difference was found for the fat/out-of-shape self-schema group, $t<1$.

Although the two groups differed according to 8th grade body weight and activity level, no association was found between group placement and menstrual status, $X^{2}=0.42, p=\mathrm{NS}$. In the 8th grade, $91 \%(n=19)$ of the fat/out-of-shape selfschema group and $85 \%(n=17)$ of the $\operatorname{sim} /$ athletic self-schema group reported having reached menarche. In the 9th grade, $100 \%$ of both groups reported having reached menarche. Also, no significant difference was found between the two groups in the age at menarche $(M=11.8$ versus $M=11.9)$, $t(33)<1$.

\section{Development of the Body Weight and Shape Self-Schema and Possible Self}

A mixed model analysis of variance followed by $t$-tests and paired $t$-tests were also used to examine the relationship between group placement and the body weight and shape self-schema scores over time. Results revealed a significant main effect for group, $F(1,35)=163.24, p<.001$. A marginally significant effect for time was also found, 
$F(1,35)=3.21, p=.08$. These effects were qualified, however, by a significant group $\times$ time interaction effect, $F(1,35)=14.07, p=.001$. Figure 1 shows the mean body weight and shape self-schema and possible self subscale scores in the 8th and 9th grade for the fat/out-of-shape and the slim/athletic self-schema groups. As expected based on the method used to form the two groups, the fat/out-of-shape group had significantly lower body weight and shape self-schema scores in the 8th grade when compared with the slim/athletic schema group, $t(27.09)=-17.98, p<.001$. This difference in self-definition, however, persisted into the 9 th grade, $t(35)=-8.08, p=<.001$. Within group comparisons, using the paired $t$-test, revealed no significant difference in mean body weight and shape self-schema scores across the 2 year period in the fat/out-of-shape self-schema group, $t(18)=$ $-1.49, p=$ NS. However, for the slim/athletic group, a significant decrease in the current body weight and shape self-schema scores was observed between the 8th and 9th grades, $t(17)=3.66, p=$ .002 .

Results of a mixed model of analysis of variance comparing body weight and shape possible self scores by group over time also revealed a significant main effect for group, $F(1,35)=11.14, p=$ .002 , and a marginally significant effect for time, $F(1,35)=3.17, p=.084$. Again these main effects were qualified by a significant group $\times$ time interaction effect, $F(1,35)=6.12, p=.02$. A significant group difference was found in the 8th grade possible self scores, with the slim/athletic subjects endorsing a slimmer and more athletic

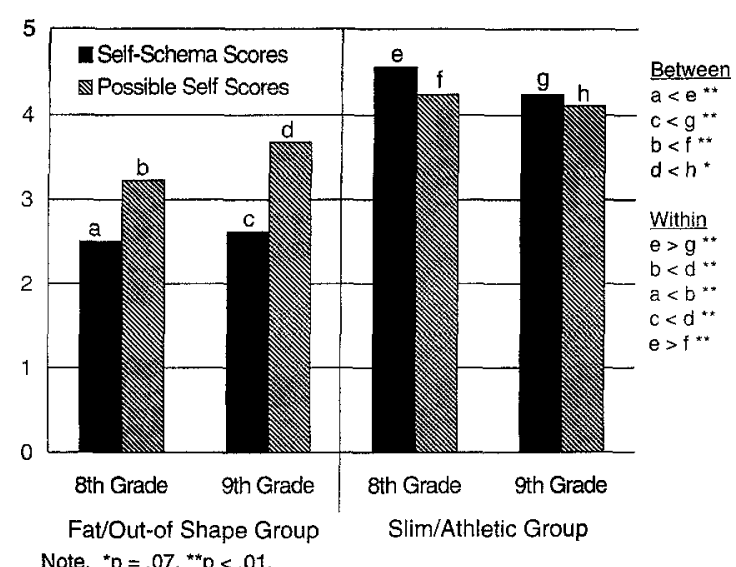
Note. ${ }^{*} p=.07 .{ }^{* *} p<.01$.

Fig 1. Body weight and shape self-schema and possible self scores for the 8 th and 9 th grades by group. possible self than those in the fat/out-of-shape group, $t(32.93)=-5.22, p<.001$. However, in the 9th grade, the difference between the two groups in the possible self score decreased in magnitude and was only marginally significant, $t(35)=-1.85, p=.07$. Results of paired $t$-tests revealed that for the fat/out-of-shape self-schema group, the mean possible self score became significantly more slim/athletic across the junior high to high school transition, $t(18)=-2.75, p=.01$. However, the possible self scores for the slim/ athletic group remained stable across the 2 years, $t(17)<1$.

Within the eating disorder literature, discrepancies between the current and desired self have been identified as an important source of motivation for the disordered eating behaviors and attitudes. As can be seen in Figure 1, the two groups differed according to the degree of the discrepancy between the body weight and shape self-schema and possible self scores. Results of paired $t$-tests revealed that the fat/out-of-shape self-schema group had significantly more slim and athletic possible selves when compared to the current self-schema in both the 8th, $t(20)=-4.56, p=<.001$ and 9th grades, $t(18)=-5.10, p<.001$. In contrast, girls in the slim/athletic self-schema group had a significantly less slim/athletic possible self when compared to the current self-schema in the 8th grade, $t(19)=$ $3.12, p=.006$. No significant difference was found between the current self-schema and possible self scores for the slim/athletic group in the 9th grade.

\section{Emotional Consequences of the Body Weight and Shape Self-Schema}

To examine the relationship between selfschema group and judgments of personal competence and self-worth, multivariate analyses of variance (MANOVA) using Wilks' criteria for significance followed by univariate analyses of variance were completed. Results revealed significant group differences on the 8th grade SPPAQ subscale scores (Wilks $\lambda=0.44$ ), multivariate $F(9$, $29)=4.12, p=.002$. Table 1 shows the 8 th grade SPPAQ subscale scores by group and the results of the univariate analyses. As can be seen, girls in the fat/out-of-shape self-schema group had significantly lower scores on the athletic competence, physical appearance, and general self-worth subscales than those in the slim/athletic schema group. No other differences were found. 
Table 1. Descriptive Statistics and Univariate Analyses of Variance Results for the Eighth Grade SPPAQ Subscales by Group

\begin{tabular}{|c|c|c|c|c|c|}
\hline \multirow[b]{3}{*}{ SPPAO Scores } & \multicolumn{5}{|c|}{ Self-Schema Group } \\
\hline & \multicolumn{2}{|c|}{ Fat/Out-of-Shape } & \multicolumn{2}{|c|}{ Slim/Athletic } & \multirow[b]{2}{*}{$F$} \\
\hline & $M$ & $S D$ & $M$ & $S D$ & \\
\hline Scholastic & 2.73 & 0.93 & 2.99 & 0.61 & 1.01 \\
\hline Social acceptance & 2.97 & 0.57 & 3.00 & 0.76 & $<1$ \\
\hline Athletic & 2.12 & 0.59 & 3.23 & 0.57 & $35.90 t$ \\
\hline Physical appearance & 1.91 & 0.60 & 2.43 & 0.57 & $7.36^{*}$ \\
\hline Jab & 3.01 & 0.66 & 2.81 & 0.60 & 1.00 \\
\hline Romantic appeal & 2.29 & 0.71 & 2.60 & 0.69 & 1.95 \\
\hline Behavioral conduct & 2.35 & 0.88 & 2.67 & 0.65 & 1.58 \\
\hline Close friendship & 3.45 & 0.56 & 3.32 & 0.68 & $<1$ \\
\hline General self-worth & 2.42 & 0.59 & 3.01 & 0.74 & $7.77^{*}$ \\
\hline
\end{tabular}

A MANOVA on the 9th grade SPPAQ subscale scores also revealed a significant group effect, (Wilks $\lambda=0.55$ ), multivariate $F(9,27)=2.49$, $p=.03$. Results of the univariate analyses are shown in Table 2. As can be seen, girls in the fat/out-of-shape self-schema group again had significantly lower athletic competence, physical appearance and marginally significantly lower general self worth scores.

An ANOVA on the depression subscale score of the SCL-90 also revealed marginally significant differences between the two groups with the fat/outof-shape self-schema group reporting higher levels of depressed feelings than those in the slim/athletic group.

Table 2. Descriptive Statistics and Univariate Analyses of Variance Results for Ninth Grade SPPAQ and HCL-90 Depression Subscale by Group

\begin{tabular}{|c|c|c|c|c|c|}
\hline \multirow[b]{3}{*}{ SPPAQ Scores } & \multicolumn{5}{|c|}{ Self-Schema Group } \\
\hline & \multicolumn{2}{|c|}{ Fat/Out-of-Shape } & \multicolumn{2}{|c|}{ Slim/Athletic } & \multirow[b]{2}{*}{$F$} \\
\hline & $M$ & $S D$ & $M$ & $S D$ & \\
\hline Scholastic & 2.76 & 0.72 & 2.87 & 0.54 & $<1$ \\
\hline Social acceptance & 2.96 & 0.61 & 3.18 & 0.70 & 1.05 \\
\hline Athletic & 2.02 & 0.63 & 3.00 & 0.76 & $18.20 t$ \\
\hline Physical appearance & 1.96 & 0.63 & 2.70 & 0.58 & $13.55 t$ \\
\hline Job & 3.15 & 0.49 & 3.06 & 0.44 & $<1$ \\
\hline Romantic appeal & 2.39 & 0.68 & 2.71 & 0.62 & 2.32 \\
\hline Behavioral conduct & 2.42 & 0.86 & 2.53 & 0.68 & $<1$ \\
\hline Close friendship & 3.61 & 0.38 & 3.47 & 0.54 & $<1$ \\
\hline General self-worth & 2.56 & 0.64 & 2.90 & 0.59 & $2.84^{*}$ \\
\hline HCL-90 & 1.49 & 0.93 & 0.97 & 0.86 & $3.17^{*}$ \\
\hline
\end{tabular}

Behavioral Consequences of the Body Weight and Shape Self-Schema

A univariate analysis of variance revealed no significant difference between the two groups on the EAT-26 total scale score. However, a MANOVA on the three subscale scores revealed a significant group difference (Wilks $\lambda=0.75$ ), multivariate $F(3,34)=3.78, p<.02$. Table 3 shows the EAT-26 total scale and subscale scores by group. As can be seen, no significant differences were found between the two groups in the bulimia nor food preoccupation subscales. However, the fat/out-of-shape selfschema group had significantly higher dieting subscale scores when compared to the slim/athletic group.

\section{Prediction of Emotional and Behavioral Consequences}

To explore the relative effects of weight and the body weight and shape self-cognitions in predicting the 9th grade self-esteem, appearance, and athletic competence and dieting subscale scores, a series of regression analyses were completed. Girls with a fat/out-of-shape or slim/athletic self-schema were included in the analyses. Pearson correlation coefficients for the body weight, self-schema, possible self, and discrepancy scores (self-schema score - possible self subscale score), shown in Table 4, generally reveal moderate to strong intercorrelations among the predictors. Because of the issue of multicollinearity, four simple regression analyses were completed for each dependent variable. In the first model, body weight was used as the predictor variable. In the second analysis, the self-schema score was used as the predictor, and in the third, the possible self score was used. Finally, in the fourth and last model, the discrepancy score was used as the predictor variable.

Results of the regression analyses are shown in Table 5. As can be seen, none of independent variables were significant predictors of the depres-

\begin{tabular}{|c|c|c|c|c|c|}
\hline \multirow[b]{3}{*}{ EAT-26 } & \multicolumn{5}{|c|}{ Self-Schema Group } \\
\hline & \multicolumn{2}{|c|}{ Fat/Otıt-of-Shape } & \multicolumn{2}{|c|}{ Slim/Athletic } & \multirow[b]{2}{*}{$t$} \\
\hline & $M$ & $S D$ & $M$ & $S D$ & \\
\hline Dieting & 11.00 & 7.02 & 6.00 & 4.36 & $6.95^{*}$ \\
\hline Bulimia & 0.95 & 1.47 & 0.58 & 1.35 & $<1$ \\
\hline Oral control & 2.37 & 2.77 & 3.68 & 3.38 & 1.72 \\
\hline Total score & 14.32 & 9.46 & 10.26 & 7.03 & 2.25 \\
\hline
\end{tabular}


Table 4. Pearson $r$ Correlation Coefficient Matrix: Body Weight and Self-Schema and Possible Self Subscale Scores

\begin{tabular}{|c|c|c|c|c|c|c|c|}
\hline Measures & 1 & 2 & 3 & 4 & 5 & 6 & 7 \\
\hline 8th grade self-schema & - & & & & & & \\
\hline Possible self & $.69 \dagger$ & - & & & & & \\
\hline Discrepancy & $.68 \dagger$ & -.06 & - & & & & \\
\hline Weight & $-.72 \dagger$ & $-.60 \dagger$ & $-.41 *$ & - & & & \\
\hline 9th grade self-schema & $.88 \dagger$ & $.49 \dagger$ & $.72 \dagger$ & $-.73 t$ & - & & \\
\hline Possible self & $.45 \dagger$ & $.66 t$ & -.02 & $-.71 \dagger$ & $.44 \dagger$ & - & \\
\hline Discrepancy & $.56 t$ & -.01 & $.77^{*}$ & -.22 & $.70 \dagger$ & $.34^{*}$ & - \\
\hline Weight & $-.65^{*}$ & $-.57 \dagger$ & $-.35^{*}$ & $.93 t$ & $-.70 \dagger$ & $-.67 \dagger$ & -.16 \\
\hline
\end{tabular}

sion subscale score. For the EAT-26 dieting and the SPPAQ global self-esteem subscales, only the 8th grade self-schema score was a significant predictor. For the appearance subscale, all of the predictor variables were significant. However, the selfschema score accounted for an additional $19 \%$ of the variance beyond that which was accounted for by weight and $15 \%$ more than was accounted for by the discrepancy score. Finally, for the athletic competence subscale, weight, the self-schema and the discrepancy scores were significant but weight

Table 5. Results of Simple Regression Analyses for Eighth Grade Weight, Self-Schema, and Possible Self as Predictors of Emotional and Behavioral Outcomes

\begin{tabular}{lll}
\hline & Beta & $R^{2}$ \\
\hline 9th grade SPPQ global self-esteem & & \\
8th grade weight & -.17 & .03 \\
8th grade self-schema & $.33^{*}$ & $.11^{*}$ \\
8th grade possible self & .14 & .02 \\
8th grade discrepancy & .31 & .09 \\
9th grade SPPQ appearance & & \\
8th grade weight & $-.39^{*}$ & $.15^{*}$ \\
8th grade self-schema & $.58 \neq$ & $.34 \neq$ \\
8th grade possible self & $.36^{*}$ & $.13^{*}$ \\
8th grade discrepancy & $.44 \dagger$ & $.19 \dagger$ \\
9th grade SPPO athletic & & \\
8th grade weight & $-.63 \neq$ & $.39 \neq$ \\
8th grade self-schema & $.58 \neq$ & $.34 \neq$ \\
8th grade possible self & .30 & .09 \\
8th grade discrepancy & .50 & $.25 \dagger$ \\
9th grade eat-26 dieting & & \\
8th grade weight & .27 & .07 \\
8th grade self-schema & $-.36^{*}$ & $.13^{*}$ \\
8th grade possible self & -.24 & .06 \\
8th grade discrepancy & -.26 & .07 \\
9th grade SCL-90 depression & & \\
8th grade weight & .14 & .02 \\
8th grade self-schema & -.27 & .07 \\
8th grade possible self & -.14 & .02 \\
8th grade discrepancy & -.23 & .05 \\
\hline \% & &
\end{tabular}

${ }^{*} p<.05$.

$\dagger p<.01$.

$\neq p<.001$. accounted for $5 \%$ of the variance beyond that of the self-schema score.

\section{DISCUSSION}

In this study we focused on the body image self-schema and possible self as conceptuallybased mental representations and explored the development and function of these structures in a sample of adolescent girls during their transition from junior high to high school. The first major aim of the study was to examine the extent to which the body weight and shape self-schema and possible self are consolidated into stable cognitive structures by middle adolescence. Although some fluctuations were detected, when considered together the pattern of results provides evidence to suggest that there is considerable stability in the content and structure of the body weight and shape cognitions by the middle adolescent years. For those girls who defined themselves as fat and out-of-shape in the 8th grade, the body weight and shape selfschema scores were highly stable across the 2 years. Girls who defined themselves as fat and out-of-shape in the 8th grade continued to do so at the same level again in the 9th grade. Furthermore, the pattern of discrepancies between the selfschema and possible self scores in the 8th and 9th grades suggests that the basic structure of the body weight and shape cognitions is also stable. For girls in the fat and out-of-shape self-schema group, the possible self scores did become significantly more slim and athletic over the 2 years. Yet for both years, the possible selves were significantly more slim and athletic than the current self-schemas suggesting that while the size of the discrepancy may shift, the basic relative structure of these representations was stable.

Although the pattern of findings for the slim and athletic self-schema group differed from that of the 
fat and out-of-shape group, evidence to support the hypothesis of stability of the body weight and shape cognitions was still found. In contrast to the highly stable scores found in the fat and out-ofshape group, the body weight and shape selfschema scores of the slim/athletic group changed across the developmental transition. Girls in the slim/athletic group described themselves as significantly less slim and fit in the 9th grade than they did in the 8th grade. However, the possible self scoresthe body weight and shape the girls expected to be in the future-remained stable across the two years. For this group of subjects, the current self-schema was never heavier than the possible self. Rather, the current self was slimmer and more athletic than the possible self in the 8th grade and no discrepancy was found in the second year.

The cause of the changes in the body weight and shape self-cognitions that were observed in both groups is unknown. Certainly, the most plausible explanation for these shifts in scores is regression to the mean in groups of subjects who initially described themselves at the extreme ends of the body weight and shape scale. However, the fact that girls in the slim and athletic group also described themselves as both heavier and less active in the 9 th grade raises the possibility that although there is general stability in the content and structure of the body weight and shape self-definition, certain aspects may still be in flux. This hypothesis is further strengthened by the fact that the activity level score is not likely to reflect random fluctuation because it is an average based on 3 separate weeks of daily diaries completed during the fall, winter, and spring terms of the 9 th grade. Although these results must be viewed with caution because of the issue of regression to the mean, they raise interesting questions about subtle differences in body image development that may occur between those who define themselves as fat and out-of-shape and those who conceptualize themselves as slim and athletic. Additional studies that trace the evolution of the body weight and shape self-schema and possible self across multiple time points from prepubescence to early adulthood are needed to more fully understand the development of these self-cognitions in varying populations of adolescent girls.

The second aim of this study was to explore the role of the body image cognitions in emotional and behavioral self-regulation. According to selfschema theory, self-schemas and possible selves include procedural knowledge that organizes and regulates emotional and behavioral responses in the relevant domain (Markus \& Wurf, 1987). The findings of this study provide evidence to support this theoretical prediction. Within our sample of middle adolescent girls, the body weight and shape self-schema was apparently sufficiently stable to influence feelings of self-esteem, competence and dieting behaviors and attitudes. Girls who were placed in the fat and out-of-shape group based on their 8th grade self-schema score had significantly lower feelings of physical appearance and athletic competence and global self-esteem in the 8th grade than those who defined themselves as slim and athletic. Furthermore, these differences persisted into the 9th grade year. In addition, girls in the fat and out-of-shape self-schema group reported significantly more dieting behaviors and attitudes and marginally significant higher levels of depressed feelings in the 9th grade than those in the slim and athletic group.

One important question that was not addressed by the group comparison analyses was the relative importance of the self-schema and body weight in predicting the emotional and behavioral outcomes. Previous studies have shown that body weight is predictive of self-esteem, emotional well-being, and disordered eating behaviors and attitudes (Crocker, Cornwell, \& Major, 1993) raising the possibility that the self-schema is a superfluous concept, offering no additional predictive power. Results of the regression analyses, however, showed that the body weight and shape self-schema score was a stronger predictor of global self-esteem, physical appearance, and dieting scores across the 8 th to 9 th grade transition than body weight. For these middle adolescent girls, the body weight and shape self-schema score was highly correlated with their self-reported body weight, yet it was the self-schema score that was most strongly predictive of the outcomes. These results suggest that the body weight and shape self-schema may act as a mediator between objective body weight and the emotional and behavioral outcomes. Rather than body weight itself shaping emotions and behaviors, it is the mental representation of the physical self that apparently acts as the internal guide of behavior.

Results of the regression analyses also provide evidence to suggest that the content of the current self-schema may be more important than the size of 
the discrepancy between the current and future self in predicting emotional distress and dieting behaviors. Finally, the results showed that although the body weight and shape possible self is strongly associated with the current conception of the self in the domain, it also is not a strong predictor of the emotional and behavioral outcomes.

The limitations of this study must be acknowledged. First, the sample size for the study is relatively small so replication with larger and more diverse samples is necessary. Second, the findings refer to subclinical levels of disordered eating behaviors and emotional distress. Whether the fat and out-of-shape self-schema eventually plays a role in the formation of a diagnosable eating disorder is, at this point in time, unknown. The findings of studies that suggest that low selfesteem, depressed affect and dieting behaviors are risk factors that are predictive of the development of a diagnosable eating disorder provide tentative evidence to suggest that the fat and out-of-shape self-schema may serve as a part of the cognitive foundation that puts one at risk (Striegel-Moore, Silberstein \& Rodin, 1986; Wilson, 1993). Additional research that traces the relationship between the body weight and shape self-cognitions and disordered emotions and behaviors is necessary to determine the long-term consequences of the fat and out-of-shape self-definition.

Despite the limitations, the results of this study provide evidence to suggest that by middle adolescence the body weight and shape self-schema is a relatively stable cognitive structure that influences emotional well-being and eating behaviors. For this sample of middle adolescent girls, defining oneself as fat and out-of-shape predicted compromised emotional well-being and involvement in eating behaviors that may compromise physical health as well. As such, these findings suggest that the development of intervention strategies that effectively influence the content of the body weight and shape self-schema holds the potential for improving emotional well-being and physical health in adolescent girls. Longitudinal studies that trace the evolution of the body weight and shape selfschema from childhood through adolescence and explore the factors that influence its formation are needed so that effective prevention and intervention strategies can be developed.

\section{ACKNOWLEDGMENT}

We would like to acknowledge David Ronis, $\mathrm{PhD}$ for the statistical advice given during the preparation of this manuscript.

\section{REFERENCES}

Adams, P., Katz, R., Beauchamp, K., Cohen, E., \& Zavis, D. (1993). Body dissatisfaction, eating disorders, and depression: A developmental perspective. Journal of Child and Family Studies, 2, 37-46.

Attie, I. \& Brooks-Gunn, J. (1989). Development of eating problems in adolescent girls: A longitudinal study. Developmental Psychology, 25, 70-79.

Brooks-Gunn, J. \& Reiter, E. (1990). The role of pubertal processes. In S. Feldman \& G. Elliott (Eds.), At the threshold: The developing adolescent (pp. 1-53). Cambridge, MA: Harvard University Press.

Brooks-Gunn, J., Warren, M., Rosso, J., \& Gargiulo, J. (1987). Validity of self-report measures of girls' pubertal status. Child Development, 58, 829-841.

Cantor, N., \& Kihlstrom, J. (1987). Personality and social intelligence. Englewood Cliffs, New Jersey: PrenticeHall.

Cash, T. (1995). Developmental teasing about physical appearance: Retrospective descriptions and relationships with body image. Social Behavior and Personality, 23, 123130.

Cash, T. \& Brown, T. (1987). Body image in anorexia nervosa and bulimia nervosa. Behavior Modification, 11, 487521.

Castro, J. \& Goldstein, S. (1995). Eating attitudes and behaviors of pre- and postpubertal females: Clues to the etiology of eating disorders. Physiology and Behavior, 58, 15-23.

Crocker, J., Cornwall, B., \& Major, B. (1993). The stigma of overweight: Affective consequences of attributional ambiguity. Journal of Personality and Social Psychology, 64, 60-70.

Derogatis, L. (1992). SCL-90-R administrations, scoring and procedures manual-II. Towson, MD: Clinical Psychometric Research, Inc.

Felts, W., Parrillo, A., Chenier, T., \& Dunn, P. (1996). Adolescents' perceptions of relative weight and self-reported weight-loss activities: Analysis of 1990 YRBS national data. Journal of Adolescent Health, 18, 20-26.

French, S., Perry, C., Leon, G., \& Fulkerson, J. (1995). Changes in psychological variables and health behaviors by dieting status over a three-year period in a cohort of adolescent females. Journal of Adolescent Health, 16, 438-447.

French, S., Story, M., Downes, B., Resnick, M., \& Blum, R. (1995). Frequent dieting among adolescents: Psychosocial and health behavior correlates. American Journal of Public Health, 85, 695-701.

Garcia, A., George, T., Coviak, C., Antonakos, C., \& Pender, N. (1997). Development of the child/adolescent activity log: A comprehensive and feasible measure of leisure-time physical activity. Manuscript submitted for publication.

Garfinkel, P. (1992). Evidence in support of attitudes to shape and weight as a diagnostic criterion of bulimia nervosa. International Journal of Eating Disorders, 11, 321-325. 
Garner, D.M. \& Garfinkel, P. (1979). The eating attitudes test: An index of the symptoms of anorexia nervosa. Psychological Medicine, 9, 273-279.

Garner, D.M., Olmsted, M.P., Bohr, Y., \& Garfinkel, P. (1982). The eating attitudes test: Psychometric features and clinical correlates. Psychological Medicine, 12, 871878.

Graber, J., Brooks-Gunn, J., Paikoff, R., \& Warren, M. (1994). Prediction of eating problems: An 8-year study of adolescent girls. Developmental Psychology, 30, 823834.

Greenwald, A.G. \& Pratkanis, A.R. (1984). The self. In R.S. Wyer \& T.K. Srull (Eds.), Handbook of social cognition (pp. 129-178). Hillsdale, NJ: Erlbaum.

Guillen, E. \& Barr, S. (1994). Nutrition, dieting, and fitness messages in a magazine for adolescent women, 19701990. Journal of Adolescent Health, 15, 464-472.

Harter, S. (1990). Developmental differences in the nature of the self-representations: Implications for the understanding, assessment and treatment of maladaptive behavior. Cognitive Therapy \& Research, 14, 113-142.

Harter, S. (1988). The self-perception profile for adolescence. Unpublished manual, University of Denver.

Harter, S. \& Monsour, A. (1992). Developmental analysis of conflict caused by opposing attributes in the adolescent self-portrait. Developmental Psychology, 28, 251-260.

Higgins, E.T. (1987). Self-discrepancy: A theory relating self and affect. Psychological Review, 94, 319-340.

Hooker, K. (1992). Possible selves and perceived health in older adults and college students. Joumal of Gerontology, 47, 85-95.

Kihlstrom, J., Cantor, N., Albright, J., Chew, B., Klein, S., \& Niedenthal, P. (1988). Information processing and the study of the self. Advances in Experimental Social Psychology, 21, 145-178.

Koff, E. \& Rierdan, J. (1991). Perceptions of weight and attitudes toward eating in early adolescent girls. Journal of Adolescent Health, 12, 307-312.

Markus, H. (1977). Self-schemas and processing information about the self. Journal of Personality and Social Psychology, 35

Markus, H., Hamill, R., \& Sentis, K. (1987). Thinking fat: Self-schemas for body weight and the processing of weight relevant information. Journal of Applied Social Psychology, 17, 50-71.

Markus, H. \& Kitayama, S. (1991). Culture and the self: Implications for cognition, emotion, and motivation. Psychological Review, 98, 224-253.

Markus, H. \& Nurius, P. (1986). Possible selves. American Psychologists, 41, 954-969.

Markus, H. \& Wurf, E. (1987). The dynamic self-concept: A social psychological perspective. In M.R. Rosenweig \& L.W. Porter (Eds.), Annual Review of Psychology, 38, 299-337.

Orenstein, P. (1994). School girls: Young women, self-esteem and the confidence gap. New York: Doubleday.

Pike, K. \& Rodin, J. (1991). Mothers, daughters and disordered eating. Journal of Abnormal Psychology, 100, 198-204.
Rieves, L. \& Cash, T. (1996). Social developmental factors and women's body-image attitudes. Journal of Social Behavior and Personality, 11, 63-78.

Rodin, J. (1993). Cultural and psychosocial determinants of weight concern. Annals of Internal Medicine, 119, 643-645.

Rosen, J.C. (1990). Body-image disturbances in eating disorders. In T.F. Cash \& T. Pruzinsky (Eds.), Body images: Development, deviance, and change. (pp. 190-213). New York: Guilford Press.

Rosenberg, M. (1986). Self-concept from middle childhood through adolescence. In J. Suls, \& A. Greenwald (Eds.), Psychological perspectives on the self Vol 3. (pp. 107136). Hillsdale, New Jersey: Lawrence Erlbaum.

Ruvolo, A. \& Markus, H. (1992). Possible selves and performance: The power of self-relevant imagery. Social Cognition, 10, 95-125.

Slap, G., Khalid, N., Paikoff, R., Brooks-Gunn, J., \& Warren, M. (1994). Evolving self-image, pubertal manifestations, and pubertal hormones: Preliminary findings in young adolescent girls. Journal of Adolescent Health, 15, 327-335.

Stein, K.F. (1996). The self-schema model: A theoretical approach to the self-concept in eating disorders. Archives of Psychiatric Nursing, 10, 96-109.

Stein, K.F. (1994). Complexity of the self-schema and responses to disconfirming feedback. Journal of Cognitive Research and Therapy, 18, 161-178.

Stein, K.F., Markus, H., \& Roeser, R. (1997). The consensual self and self-esteem in American adolescent girls and boys. Manuscript submitted for publication.

Strauman, T., Vookles, J., Berenstein, V., Higgins, E.T. (1991). Self-discrepancies and vulnerability to body dissatisfaction and disordered eating. Journal of Personality and Social Psychology, 61, 946-956.

Striegel-Moore, R.H., Silberstein, L.R., \& Rodin, J. (1986). Toward an understanding of risk factors for bulimia. American Psychologist, 41, 246-263.

Szymanski, M. \& Cash, T. (1995). Body-image disturbances and self-discrepancy theory: Expansion of the body-image ideals questionnaire. Journal of Social and Clinical Psychology, 14, 134-146.

Taylor, S.E. \& Crocker, J. (1981). Schematic bases of social information processing. In E.T. Higgins, C.P. Herman, \& M.P. Zanna (Eds.). Social cognition The Ontario Symposium (pp. 39-88). Hillsdale, New Jersey: Lawrence Erlbaum.

Wardle, J. \& Marsland, L. (1990). Adolescent concerns about weight and eating: A social-developmental perspective. Journal of Psychosomatic Research, 34, 377-391.

Wigfield, A., Eccles, J., Mac Iver, D., Reuman, D., \& Midgley, C. (1991). Transitions during early adolescence: Changes in children's domain-specific self-perceptions and general self-esteem across the transition to junior high school. Developmental Psychology, 27, 552-565.

Wilson, G.T. (1993). Relation of dieting and voluntary weight loss to psychological functioning and binge eating. Annals of Internal Medicine, 119, 727-730. 